\title{
BREXIT CONSEQUENCES - RELOCATION OF THE EUROPEAN MEDICINES AGENCY
}

\author{
Petya Trendafilova ${ }^{1}$, Tatyana Benisheva ${ }^{1}$, Dobriana Sidjimova $^{1}$, Bilyana Polyakova $^{2}$ \\ ${ }^{1}$ Faculty of Public Health, Medical University of Sofia \\ ${ }^{2}$ Bulgarian Association for Drug Information (BADI)
}

\begin{abstract}
INTRODUCTION: The UK decision to leave the European Union (BREXIT) has many potential consequences for the health of European citizens. One of the actions already taken has been the decision to move the location of the European Medicines Agency (EMA) from Canary Wharf in London to Amsterdam from April 2019.

AIM: The aim of this article is to analyze the EU criteria for the process of EMA relocation from London to Amsterdam based on the comparison of the EMA bids placed by the EU candidates and the indicators among those member states (MSs).
\end{abstract}

MATERIALS AND METHODS: Documentary and analytical methods are used to provide scientific data on the decision of EMA relocation from London to Amsterdam and the consequences of BREXIT from a drug policy point of view. Many different indicators, like accommodation, living cost were compared and surveyed in the MSs.

RESULTS: EU opened procedure for EMA relocation after BREXIT in 2017. A total of 19 cities have applied to host the EMA headquarters, including Bulgaria, with Amsterdam winning the battle. EMA is working with the Dutch authorities and the relocation of EMA to Amsterdam is a fact.

Bulgaria, Hungary, and Croatia were the top three countries with the lowest possible living costs, and accommodation.

CONCLUSION: After EMA relocation to Amsterdam as a result of BREXIT, the pharmaceutical industry is dealing with significant implications in order not to lose its market access. Many innovative and generic medicines across the MSs updated their marketing authorizations due to the fact that the exclusion of the UK from all medicines authorization procedures should have been finalised by the end of March 2019 .

Keywords: medicinal products, marketing authorization, BREXIT consequences, EMA relocation applications, cost living indicators

\footnotetext{
Address for correspondence:

Tatyana Benisheva

Faculty of Public Health

Medical University of Sofia

8 Byalo More St

1527 Sofia

e-mail:benishevatb@gmail.com
}

Received: May 14, 2019

Accepted: June 29, 2019

\section{INTRODUCTION}

The UK referendum in May 2016 has launched the country's exit from the EU and the UK decision to leave the European Union. BREXIT has many potential consequences for the health of European citizens.

The relocation of the European Medicines Agency (EMA) from London to Amsterdam is ex- 
tremely important due to health, administrative, and financial consequences.

In order not to break the EU legislation (Regulation 726/2004) on placing the evaluated medicinal products within the foreseen deadlines, the process should have been finalized by 31 March, 2019.

An action already taken consisted of moving EMA from Canary Wharf in London to Amsterdam at the end of March 2019.

The UK's withdrawal from the European Union - BREXIT will affect many healthcare aspects and social care in the United Kingdom. The questions associated with the impact of BREXIT on health and social care are complex and one of them is the EMA relocation from London to the Netherlands. On the basis of the written evidence six areas in particular where BREXIT will have a critical effect in health and trade area have been identified. They are as follows (1):

$\diamond$ The UK's health and social care workforce both those who are there, and those who will be needed in the future;

$\diamond$ Reciprocal healthcare coverage and cross-border health care;

$\diamond$ Medicines, products, medical devices, clinical trials and wider health research;

$\diamond$ Public health, including environmental protections and communicable diseases;

$\diamond$ Resources, including EU agencies, funding programs, networks and health in overseas aid;

$\diamond$ Market functioning and trade agreements.

As a result of this decision, a major competition for the relocation of two of the EU agencies based in London, namely EMA and the European Banking Authority (EBA), started in 2017 (2).

EMA has been in place since 1995 in London and is responsible for the evaluation and supervision of all medicinal products for human and veterinary use in terms of their safety, efficacy and quality. The Agency's primary task is to coordinate scientific expertise and resources of the MSs in the field of medicines in terms of the centralised procedure, which included 28 Member States (MSs) and the European Economic Area EEA (Norway, Lichtenstein, and Iceland) (3).
As a result of BREXIT, on 20 November 2017, EU MSs decided to relocate EMA from London to Amsterdam (the Netherlands). The Agency have been working with the Dutch authorities since end of 2018 for the relocation and took up its operations in Amsterdam on 30 March 2019 (2).

The Dutch authorities have committed to building completely new permanent premises for EMA in the Zuidas business district, which is expected to be available from 15 November 2020.

\section{AIM}

This paper aims to analyse the EU criteria for the process of EMA relocation from UK to the Netherlands by basing them on a comparison of the EMA bids of the EU candidates, and compare and survey the indicators among those MSs.

\section{METHODS}

Documentary and analytical methods are used to provide scientific data on EMA relocation from London to Amsterdam and the consequences of BREXIT from a drug policy point of view. The Big Mac index is used in the study as an indicator for the living standard in MSs.

1. Documentary method is used. MSs applications, websites and videos, online references for EMA hosting have been reviewed.

2. Analytical method is used, based on several cost indicators (monthly rental cost indicators for expensive and non-expensive residential areas as well as for food and public transport) based on published official EU data.

3. Graphic method is used to illustrate and to compare the different indicators chosen.

\section{DISCUSSION}

\section{Procedure Leading up to a Decision on the EMA Relocation and Voting}

The EU Joint Statement refers to the desirability of the geographical spread and to the objective agreed on by the leaders in 2003 and upheld in 2008 to give priority to acceding States in the distribution of seats of other agencies set up in the future (5).

The Commission has examined the MS bids received for the EMA relocation within the deadline (31 July 2017) and has provided an assessment of these based on the pre-set unweighted criteria $(4,5)$. 
Petya Trendafilova, Tatyana Benisheva, Dobriana Sidjimova et al.

Five criteria have been set for the EMA applications, namely: (4)

Criterion 1: The assurance that the agency can be set up on site and take up its functions at the date of the United Kingdom's withdrawal from the Union (adequate office logistics);

Criterion 2: Location accessibility;

Criterion 3: The existence of appropriate education facilities for agency staff's children;

Criterion 4: Appropriate access to the labour market, social security and medical care, both for children and spouses;

Criterion 5: Business continuity.

This assessment has served the purpose of informing the decision-making process. The decision for EMA relocation has been taken by a voting process whose outcome the MSs agreed in advance to abide by. To allow for a smooth and timely relocation of the EMA, the objective was to reach a decision on the new location in the autumn of 2017. The decision was taken on the sidelines of the General Affairs Council (based on Art. 50) in November 2017 (Fig. 1).

The Commission has examined and assessed the applications of the MSs based on the criteria agreed by the Commission and the European Council announced its decision on 30 September 2017. Then the voting process in the Council of Ministers based on the above five criteria has begun with guarantees that the Agency will take up its functions on

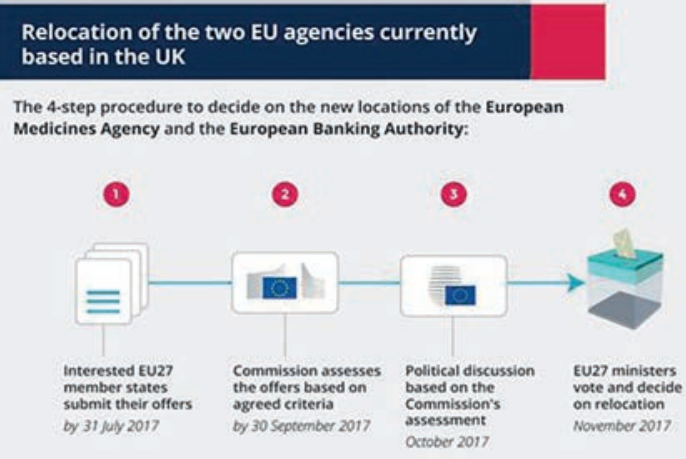

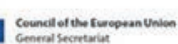

Fig. 1. The 4-step procedure to decide on the EMA new location by the Council of $E U(8)$ the day of UK's withdrawal from the EU, which was scheduled and performed on 29 March 2019 by treaty $(6,7,8)$, (Fig. 1).

\section{Submitted Applications for EMA Hosting}

A total of 19 applications for EMA hosting in alphabetical order in 19 cities in the EU were presented on the website of the Council of Europe at the beginning of August 2017. The cities were Amsterdam, Athens, Barcelona, Bonn, Bratislava, Brussels, Bucharest, Copenhagen, Dublin, Helsinki, Lille, Malta, Milan, Porto, Sofia, Stockholm, Vienna, Warsaw and Zagreb. Therefore, Sofia was competing against 18 other European cities (4).

The bids varied from 4 pages for Sofia to 156 pages for Barcelona. A large number of EMA candidates (19 MSs) have offered different supporting materials such as country brochure, websites, and videos presenting their main strengths and trying to prove that the cities they present meet all five criteria.

The Council of Ministers of Bulgaria adopted the decision to put forward Sofia's candidacy and the city application was prepared and submitted on 31 July 2017, keeping in mind that the deadline was no later than 01 August 2017. The most detailed offers (over 100 pages) were those of Barcelona, Bucharest and Dublin, while the shortest were presented by $\mathrm{Za}$ greb, Warsaw and Sofia. From a formal point of view, it was expected that all countries were in line with the assessment criteria set by the EU leaders. Obviously the competition was serious and many other factors have been taken into consideration (7) (Fig. 2).

\section{Video Applications and Websites of the 19 MSs Applying for EMA Hosting}

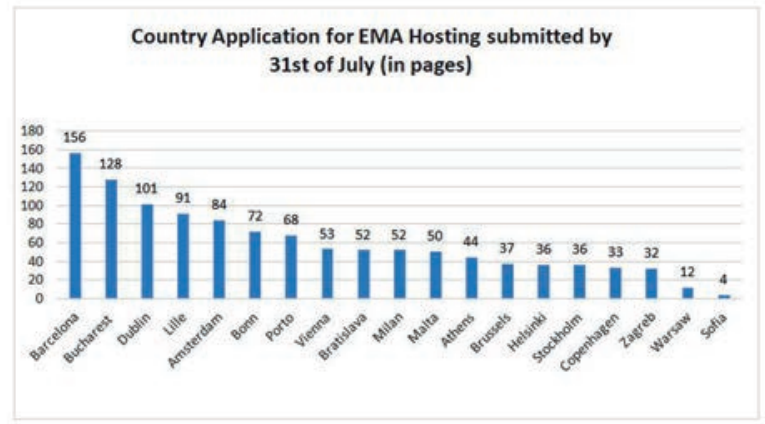

Fig. 2. Country applications/offers for EMA hosting in 19 MSs (in pages) (4) 
Following the most popular channel of advertising, most candidate cities - 15 MSs (79\%) (out of $19 \mathrm{MSs}$ ) provided websites and 8 MSs (42\%) (out 19 MSs) offered videos about their most attractive features (Fig. 2), (Table 1) (4).

Some of the applications relied on being popular business destinations like Amsterdam, Dublin and Bonn. The advertising campaigns of Copenhagen and Dublin both included their prime ministers in the video applications they submitted.

Barcelona applied with two instead of one video ad. The Sofia and Brussels bids had no video ads at the time of submission. Audio materials for Sofia were prepared after the deadline of 31 July. The Bulgarian government created an EMA website with two videos but they were not among the documents sub-

Table 1. Applicant cities for EMA hosting among 19 MSs (number of websites and videos) (4)

\begin{tabular}{lccc} 
№ & Applicant City & Website & $\begin{array}{c}\text { Video } \\
\text { Presentation }\end{array}$ \\
1 & Amsterdam & 1 & - \\
2 & Athens & 1 & - \\
3 & Barcelona & - & 2 \\
4 & Bonn & 1 & - \\
5 & Bratislava & 1 & - \\
6 & Brussels & 1 & - \\
7 & Bucharest & 1 & - \\
8 & Copenhagen & 1 & 1 \\
9 & Dublin & - & 1 \\
10 & Helsinki & 1 & - \\
11 & Lille & 1 & 1 \\
12 & Malta & 1 & - \\
13 & Milan & 1 & 1 \\
14 & Porto & 1 & - \\
15 & Sofia & - & - \\
16 & Stockholm & 1 & 1 \\
17 & Vienna & 1 & - \\
18 & Warsaw & - & 1 \\
19 & Zagreb & 1 & - \\
Total & & 15 & 8 \\
\hline
\end{tabular}

mitted to the Commission as of 31 July 2017. (https:// www.youtube.com/watch?v=SSHhT0X96-I)

Other applicants' video ads, such as those of Milan and Zagreb, included more focus on their cities as tourist destinations. Sweden focused on the scientific and innovation activities in the country, which was in line with EMA initiatives. (Table 1).

Each host city highlighted its advantages and presented the availability of the city's infrastructure, educational facilities, buildings or future EMA building and connectivity/flights from/to other countries and cities (4).

The procedure of voting for EMA relocation from UK in October 2017 was organised in several rounds. In the first round of voting, each MS was entitled to one vote. Voting consisting of 6 points was distributed as follows: three points for the preferred application, two for that application ranked second, and one for the third bid. The city proposal scoring 3 points from at least 14 MSs was considered as selected. Applications of cities with the most votes proceeded to a second round where each MS voted one point. In the third vote, the bid, which received the highest number of votes was selected. For the Presidency, lots were drawn and Amsterdam won (9).

\section{Comparison of Indicators Among the MS Applying for EMA Host}

The winning country will feel the effect in terms of not only the pharmaceutical field but all sectors of the economy, including hotel accommodation, and the entire infrastructure- airports, roads and highways will be influenced.

The host has to provide accommodation conditions for the Agency staff and their families; therefore, these factors have been analysed.

\section{Comparison of Rental and Living Cost in the 19 MSs Applied for EMA Host}

The EMA building in London was located on an area of 27,000 sq. m., including a reception area, conference rooms, offices, and auditoriums, which is suitable for the seven Committees and several working parties and CMD to cover their regular agenda. According to last year's data of EMA, 30,000 hotel stays have been booked for the agency's work, with a daily capacity of 350 hotel rooms at peak times. A total of 648 children of EMA staff, aged 0-18, were enrolled in September 2016 at a school, kindergarten, 


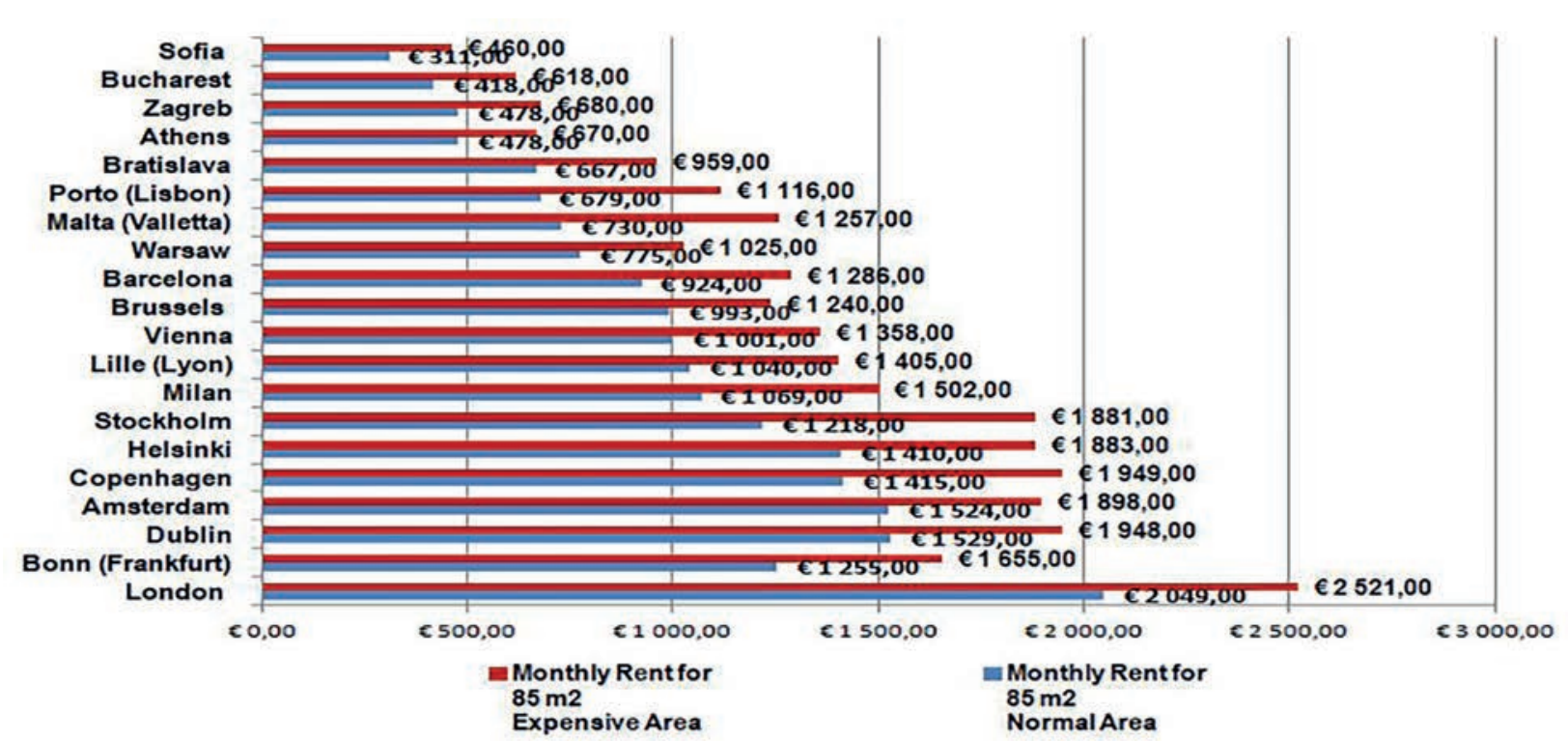

Fig. 4. Cost in $€$ of monthly rent for a $85 \mathrm{~m}^{2}$ housing area in expensive and non-expensive areas in the MSs candidate cities (August 2017) and London (EMA location before 30 of March 2019) (10)

nursery or university. There used to be 117 kindergartens, 96 preschools, 231 primary schools, 149 high schools and 55 universities involved (9). According to data cited on the Belgium website, the EMA's maintenance (accommodation and others) in London would cost around EUR 40 million, in France it would be around EUR 20 million, and in Amsterdam around EUR 10 million. If EMA was relocated to Sofia, its maintenance would have been approximately EUR 3.5 million - the lowest cost possible, which is 13 times cheaper than in London, 6 times cheaper than in France and almost 3 times cheaper than in Amsterdam (Fig. 3), (4).

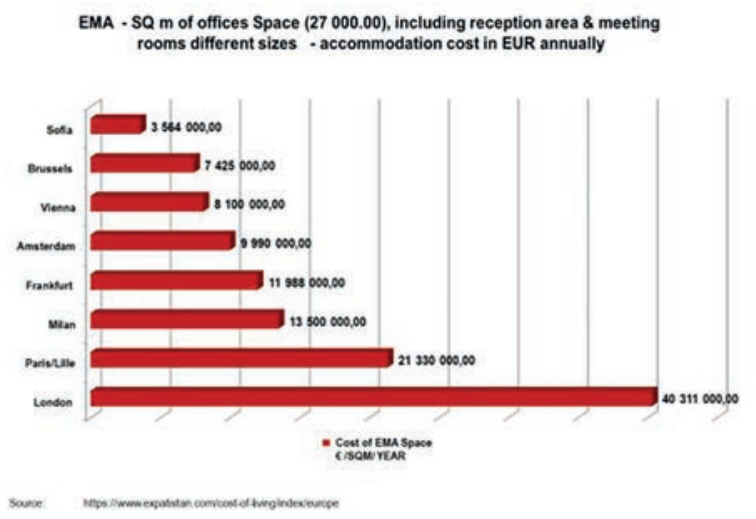

Fig. 3. Accommodation cost of EMA office space (data for Sofia per Belgium EMA website) (4)
The rental cost per square meter in the cheapest and the most expensive areas in Sofia, Zagreb and Bucharest ranged from $460 €$ to $680 €$ with Sofia being almost 4 times less expensive than Stockholm (1881€), Amsterdam (1898€), Copenhagen (1949€) and Bonn (1655€), and 3 times less than Lille, France (1405€) (Fig. 4).

These cumulative economic factors have been neglected even though it has been clear that Bulgaria, Zagreb, and Bucharest offer the most reasonable economic conditions regarding accommodation $(4,10)$.

The Big Mac index is used in the study as an indicator of the living standard in the MSs. It was invented by The Economist in 1986 as a guide to es-

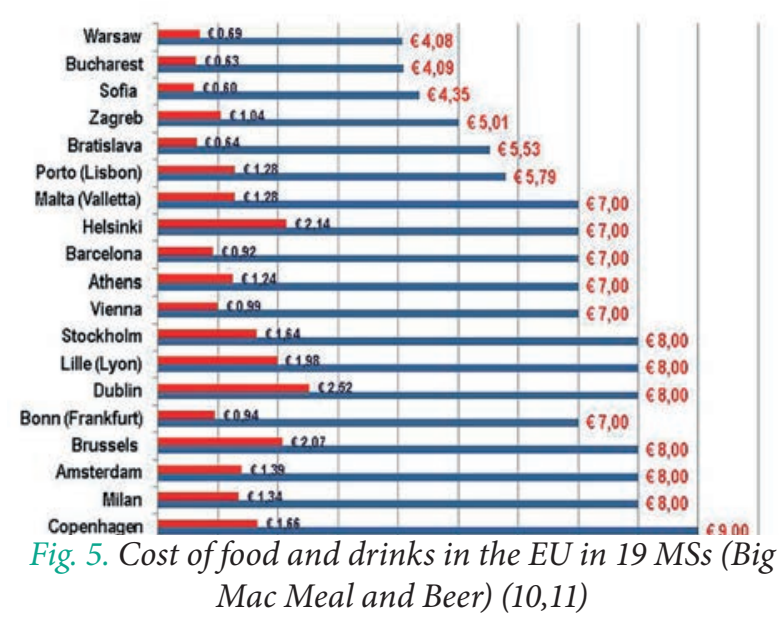


tablish whether currencies in the different countries are at their "correct" level. The index is based on the theory of purchasing power parity (PPP), the notion that in the long run exchange rates should move towards the rate that would equalise the prices of an identical basket of goods and services (in this case, a Big Mac burger) in different countries (10). Bulgaria was in the top three (Warsaw, Bucharest, Sofia) with the lowest possible prices for selected food and drinks and other living costs, public transport tickets, and the Internet. Unfortunately these economic indicators for rental and living cost were not among the comparison for the EMA relocation (11) (Fig. 5).

In such important EU processes where all MSs are involved and affected, the financial criteria should also be a part of the procedure to ensure the final political decision on behalf of EU citizens is adopted based on transparent and objective criteria in the interest of the whole EU population. Unfortunately, the economic criteria were not requested in the EU procedure and it was a non-discussable matter at all. In the new EU environment, where the UK will no longer financially contribute to the EU economic landscape, all these financial impacts would be appropriately evaluated and discussed.

6. Number of Flights Connection per Week from the Candidates Which Applied for EMA Host

EMA coordinates the work of 7 scientific committees and is supported by 34 working parties and advisory groups who meet regularly, in many cases monthly. Almost all of these meetings are attended by delegates from all MSs of the EEA as well as some non-member countries.

In 2016 a total of 36,000 visitors (staff of competent national authorities, scientists, patients, health professionals, industry), including 4000 non-EU visitors requiring intercontinental flights (US, Japan, Korea, etc.), have come to the Agency for meetings which last up to 4 days. A total of 30,000 hotel nights have been booked, with a daily peak hotel capacity requirement of 350 rooms $(4,9)$.

Some applicants (MSs) have submitted for schedules of weekly direct flights from the proposed city to different destinations in the EU. All cities that have been candidates for EMA hosting have had a daily flight, with two or more airlines and flight con- nections which have been summarised weekly, where Sofia even has better connections than Zagreb, Warsaw, Athens, Stockholm and Budapest $(4,9)$.

7. The EU Procedure for EMA Relocation from London to Other MS and Preparedness of EMA Staff

To complement the European Commission's assessment of all bids for the relocation of the Agency submitted by MSs, EMA presented the results of its staff retention survey at the end of September 2017, before the end of the official EU procedure, which according to the EMA documents raised serious concerns. The survey was launched on 4 September 2017 in the context of EMA's business continuity planning, after all host candidacies were known and EMA staff had the opportunity to study in detail the 19 MS offers.

This was to complement the European Commission's assessment of all bids for the relocation of EMA submitted by MSs that have been published at the end of September (Fig. 1).

Four clusters of candidate cities have emerged:

$\diamond$ The first cluster included those cities to which $65 \%$ or more of EMA staff indicated they are likely to move.

$\diamond$ The second cluster was the cities where staff retention would range between 50 and $64 \%$.

$\diamond$ The third cluster includes cities to which between 30 and $49 \%$ of staff were likely to move.

$\diamond$ The fourth cluster was those cities where less than $30 \%$ of EMA staff said they would move to (10).

EMA is a networking organisation whose activities involve thousands of experts from across EU. These experts carry out the work of the EMA's scientific committees and they are not part of the employed staff. The Agency's staff supports the Management Board and the Executive Director in carrying out their responsibilities, including administrative and procedural aspects of EU law related to the evaluation and safety-monitoring of medicines. The EMA staff is not involved in the scientific evaluation of medicines that are covered by the EMA representatives from each MS.

The EMA survey mentioned above was not quite clear on the indicators which were taken into consideration because the methodology of the survey 
Petya Trendafilova, Tatyana Benisheva, Dobriana Sidjimova et al.

management tool was not published in the EMA document from 26 September 2017 EMA/635491/2017. The survey demonstrated that for $65 \%$ of EMA staff the new EMA location would be a determining factor in their decision on whether to relocate or not. It was unclear whether this survey was based on certain insiders, perceptions or specific information of EMA staff about each appointed candidate city in the EU (12).

\section{Procedure for the Relocation of the UK- based EU Agencies}

The Steps of the Relocation Procedure (13)

The procedure consisted of 19 bids by member states to host one or both of the agencies, submitted by 31 July 2017, assessment of the bids by the Commission based on the agreed criteria published on 30 September 2017, political discussion based on the Commission's assessment within the GAC (Article 50) meeting on 17 October 2017, and a voting procedure by the 27 member states within the GAC (Article 50) meeting on 20 November 2017.

\section{Assessment Criteria}

On 22 June 2017, 27 EU leaders agreed on 6 general criteria:

$\diamond$ assurance that the agency is operational when the UK leaves the EU,

$\diamond$ accessibility of the location,

$\diamond$ schools for the agency staff's children,

$\diamond$ access to the labour market and healthcare for employees' spouses and children,

$\diamond$ business continuity,

$\diamond$ geographical spread.

On 30 September, the European Commission published the assessment of the bids based on the 6 criteria agreed through EU28 as well as the procedure leading to a decision on the relocation of the European Medicines Agency and the European Banking Authority in the context of the UK's withdrawal from the Union (22/06/2017). On the same day, the Commission submitted its assessment of the offers to the Secretary-General of the Council. The assessment consisted of the following documents:

$\diamond$ Commission note

$\diamond$ General assessment summary, one for each Agency $\diamond$ Individual assessment summaries, one for each bid

$\diamond$ Individual assessment grids, one for each bid

The EMA prepared all these individual assessment summaries and grids for each candidate as well as a general assessment summary based on the individual MS assessment. The 5 criteria were split into a template with many subcriteria that were not published at the beginning of the EU procedure before the submission of the application, together with the main 5 criteria (13).

At the end of November, the European Council, represented by the ministers, voted for the new location of EMA.Out of the 19 candidate countries participating in the EMA competition, the Netherlands (NL), Slovakia (SK), Belgium (BE), Denmark (DK), France (FR), and Italy (IT) fulfilled the criteria in the first round.

At the next stage, the battle was between Amsterdam and Milan. In addition, in the final round, the decision was in favour of Amsterdam, which was chosen as the most suitable candidate for EMA adoption. On 20 November 2017, EU member states decided to relocate the EMA to Amsterdam, the Netherlands. The Agency immediately began working with the Dutch authorities to prepare for the move and take up its operations in Amsterdam by 30 March 2019 (14).

\section{New Tracking Tool for EMA Relocation to Amsterdam - November 2017}

EMA and the Netherlands finalized a Seat Agreement text, which described how the Dutch government would treat EMA, its bodies and its employees once they start operating in the Netherlands so that EMA could function properly and independently in the Netherlands (Fig. 6).

The Dutch government and EMA completed the negotiations earlier than anticipated and signed the agreement to enable EMA to prepare for a smooth transition of the work of its scientific units and delegates, and allow EMA staff and their families to smooth settle in the Netherlands.

EMA and the Netherlands agreed on a joint governance structure to steer and oversee the relocation project. The preliminary plans were to progress activities within five work streams of temporary prem- 


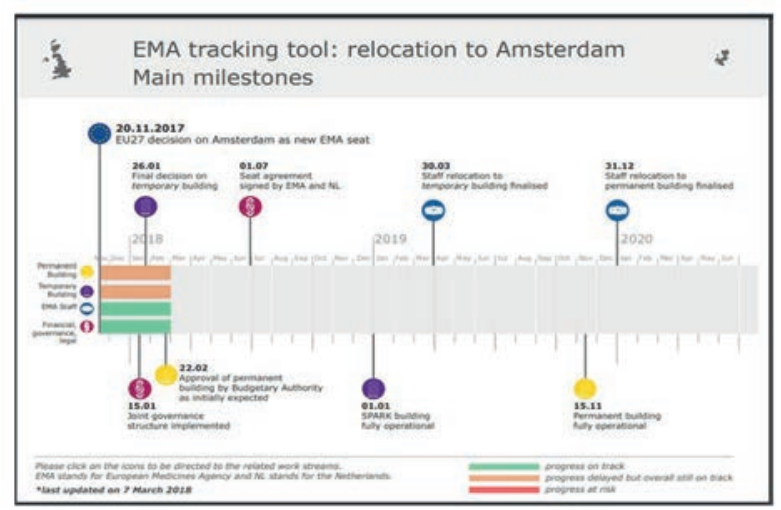

Fig. 6. EMA tracking tool: relocation to Amsterdam (main milestones) (15)

ises, permanent premises, staff relocation, financial and legal aspects, and external communication.

Following the EU28 decision to relocate EMA to Amsterdam, a joint governance structure was agreed between EMA and the Netherlands with the five work streams mentioned above.

On 28 February 2018, EMA's Management Board voted on a revised offer of the Dutch government regarding the Agency's new permanent premises in Zuidas and endorsed the notification to the EU's Budgetary Authority (comprising the European Council and European Parliament) of EMA's intention to move to the new building.

The Dutch government offered temporary premises to EMA, the Spark building in the Sloterdijk area of Amsterdam, from 1 January 2019 until its permanent building is completed.

EMA left its London premises on 1 March 2019 to relocate to Amsterdam. From 4 March 2019, the official address of the Agency is that of its permanent building in Amsterdam Zuidas (15).

EMA's new permanent headquarters, a tailormade building in the Zuidas business district of Amsterdam, is planned for completion on 15 November 2019 (16).

This is a key step in the building approval process. If it receives the assent of the Budgetary Authority, EMA can enter into a contractual obligation for its final premises. EMA has published a new tool showing the main milestones and deliverables for the Agency's move to Amsterdam. Because of its important role in safeguarding public and animal health in the European Union (EU), EMA is committed to giving stakeholders and the full public visibility of the relocation project. The tracking tool will allow all interested parties to follow the progress made (15).

The tracking tool is a living document - updated every month - in which milestones might be added as the project progresses. The tracking tool first gives a general overview of the main milestones agreed for each of the work streams, except external communication, which is an ad-hoc activity dependent on the progress made with the other work streams. It then outlines in more detail the deliverables for each work stream, highlighting clearly on track to meet them. (15).

EMA lost 128 (14\%) experts of the staff at the relocation. A total of $451(\mathbf{5 7 \%})$ had already relocated to the Netherlands (57\%), 312 (39\%) members of staff were teleworking, 28 - on long-term leave (4\%). There would definitely be high interest in each new open vacancy at EMA (16).

\section{Reactions About EMA Relocation to Am- sterdam - Italy Tried to Overturn the Decision}

Italy asked the EU to reconsider the option of relocating EMA to Milan. There were concerns about the Agency's planned move to Amsterdam. This is ahead of the scheduled completion of a new building to house the EMA in south Amsterdam, starting in 2020 (17).

The Milan administration said that Italy would have lodged an appeal against the decision to relocate the EMA to Amsterdam, which did not have an appropriate temporary building ready to house it. They acknowledged that the chances of overturning the decision to send EMA to Amsterdam were "not very high, but we should try it". However, the appeal was not sent to the European Court of Justice $(17,18)$.

The Dutch Health Ministry supported the EMA to occupy the Spark building in western Amsterdam during 2019.

\section{CONCLUSION}

The competition on the EMA relocation procedure had a political basis involving the prime ministers of the MSs part of the European Council.

After the EMA relocation, the pharmaceutical industry has been dealing with significant implications in order not to lose its access to many innova- 
Petya Trendafilova, Tatyana Benisheva, Dobriana Sidjimova et al.

tive and generic medicines across the MSs. The relocation procedure was extremely important due to administrative, technical and financial issues needed to abide by the EU legislation (Regulation 726/2004) for placing the evaluated medicinal products within the foreseen deadlines.

EMA offers prestige to its host, along with an influx of high-spending officials and experts. The relocation of the EMA is more than a symbolic act as it shows what London loses and Amsterdam gains as the new pharmaceutical capital in the EU.

The most important thing is that it can take the form of a competition and it shows exactly where the EU stands right at this moment. In this regard, this competition is charged with patriotism, enthusiasm, and emotional charge, and based on the video applications it was demonstrated that the local governments were seriously engaged.

In order to ensure public health prevention and provide access to pharmaceutical products the European political institutions, European Commission and EMA, despite the serious relocation challenges, have established processes for the marketing authorisation procedures to exclude UK as an EMA host, and from the authorisation processes and from the EU regulatory documents until 30 March 2019. The marketing authorisation holders could not place these medicinal products on the EU market after the BREXIT deadline due to the fact that no EU transitional licence possibilities of medicines with UK involvement are foreseen.

No economic criteria of the EMA relocation the different cities were provided, compared and discussed. The competition provided a significant opportunity for investors. It represented a positive talk about the freedom of movement of people and experts, and that they are welcome anywhere in the EU.

In such serious EU projects where all MSs are involved, the financial criteria should also be part of the procedure in order to be sure that the final political decision made on behalf of EU citizens is made on transparent and objective criteria, because it is in the interest of the whole EU population. We do also hope that this will be included in the future procedures for the establishment or relocation of any structure in the EU.

\section{REFERENCES}

1. Brexit and health and social care - people \& process Eighth Report of Session 2017 House of Commons Health Committee, http://www.politico.eu/ wp-content/uploads/2017/04/BrexitHealthCare.pdf (Access 21 of June 2019)

2. Relocation of the UK - based EU agencies, https:// www.consilium.europa.eu/en/policies/relocationlondon-agencies-brexit/ (Access 21 of June 2019)

3. EMA, About us. What we do, https://www.ema. europa.eu/en/about-us/what-we-do (Access 21 of June 2019)

4. Offers to host the European Medicines Agency (EMA) https://www.consilium.europa.eu/en/ policies/relocation-london-agencies-brexit/ema/ (Access 21 of June 2019)

5. EU Joint Statement refers of geographical spread of agencies - 2003 and upheld in 2008 https://europa. eu/european-union/sites/europaeu/files/docs/body/ joint_statement_and_common_approach_2012_ en.pdf (Access 21 of June 2019)

6. Benisheva T., P. D. Trendafilova, D. A. Sidgimova. The Future of the European Medicines Agency (EMA) after Brexit from a Drug Policy Point of View. Proceeding Book, 1st International Conference on Public Health "From European to National Health Policy", 9-10 October, 2017, ISBN 978-954-9318-87-6, p.34-43.

7. Procedure leading up to a decision on the relocation of the European Medicines Agency and the European Banking Authority in the context of the United Kingdom's withdrawal from the Union https://www.consilium.europa.eu/media/21503/22euco-conclusions-agencies-relocation.pdf (Access 21 of June 2019)

8. Infographic - Brexit: relocating UK-based EU agencies https://www.consilium.europa.eu/en/ infographics/eu-agencies-relocation/ (Access 21 of June 2019)

9. Marini A. Race for the Relocation of Two EU Agencies Has Begun http://www.euinside.eu/en/news/ the-race-for-relocation-of-eu-agencies-has-begunthe-winner-is (Access 21 of June 2019)

10. Expatistan's Cost of Living Map of Europe https:// www.expatistan.com/cost-of-living/index/europe (Access 21 of June 2019)

11. Rogoff $K$. The Purchasing Power Parity Puzzle, Journal of Economic Literature, Vol. 34, No. 2 (Jun., 1996), pp. 647-668 
12. European Medicines Agency EMA business continuity planning and impact of staff retention scenarios from the EMA Page 1/626 September 2017 EMA/635491/2017 https://www.ema.europa. eu/en/ documents/other/ema-business-continuityplanning-impact-staff-retention-scenarios-emastaff-survey_en.pdf (Access 21 of June 2019)

13. Procedure leading up to a decision on the relocation of the European Medicines Agency and the European Banking Authority in the context of the United Kingdom's withdrawal from the Union https://www.consilium.europa.eu/media/21503/22euco-conclusions-agencies-relocation.pdf (Access 21 of June)

14. REGULATION OF THE EUROPEAN PARLIAMENT AND OF THE COUNCIL amending Regulation (EC) No 726/2004 as regards the location of the seat of the European Medicines Agency - Brussels, 30 October 2018, https://www. consilium.europa.eu/media/36908/text-relocationema-agency-en18.pdf_(Access 21 of June)

15. EMA tracking tool: relocation to Amsterdam Main milestones https://www.ema.europa.eu/en/ documents/other/ema-tracking-tool-relocationamsterdam-main-milestones_en.pdf (Access 21 of June 2019)

16. Rasi G. Relocation of EMA, challenges and consequences, 21st DGRA Annual Congres 23 May, Bonn, Germany (Presented by Prof Guido Rasi, Executive Director) https:/dgra.de/media/pdf/ fortbildung/kongresse/2019/kongress2019_1_1_ rasi.pdf

17. Hardy C. Brexit battles: Italy tries again for the EMA, https://www.euronews.com/2018/01/31/ brexit-battles-italy-tries-again-for-the-ema (Access 21 of June 2019)

18. Paun C. Milan mayor: Italy to appeal EMA relocation. https://www.politico.eu/article/milan-mayoritaly-to-appeal-ema-relocation-today/ (Access 21 of June 2019) 